\title{
Mission Sizing and Trade Studies for Low Ballistic Coefficient Entry Systems to Venus
}

\author{
Soumyo Dutta \\ Daniel Guggenheim School of \\ Aerospace Engineering, \\ Georgia Institute of \\ Technology, \\ 270 Ferst Drive \\ Atlanta, GA 30332 \\ 404-894-7783 \\ soumyo.dutta@gatech.edu
}

\author{
Brandon Smith \\ NASA Ames \\ Research Center, \\ Moffett Field, CA 94035
brandon.p.smith@nasa.gov \\ Moffett Field, CA 94035
brandon.p.smith@nasa.gov
}

Dinesh Prabhu

ERC Inc.,

NASA Ames

Research Center,

Moffett Field, CA 94035 ethiraj.venkatapathy-1@ nasa.gov

dinesh.k.prabhu@nasa.gov

\author{
Ethiraj Venkatapathy \\ NASA Ames \\ Research Center, \\ Moffett Field, CA 94035
}

\begin{abstract}
The U.S and the U.S.S.R. have sent seventeen successful atmospheric entry missions to Venus. Past missions to Venus have utilized rigid aeroshell systems for entry. This rigid aeroshell paradigm sets performance limitations since the size of the entry vehicle is constrained by the fairing diameter of the launch vehicle. This has limited ballistic coefficients $(\beta)$ to well above $100 \mathrm{~kg} / \mathrm{m}^{2}$ for the entry vehicles. In order to maximize the science payload and minimize the Thermal Protection System (TPS) mass, these missions have entered at very steep entry flight path angles $(\gamma)$. Due to Venus' thick atmosphere and the steep- $\gamma$, high- $\beta$ conditions, these entry vehicles have been exposed to very high heat flux, very high pressures and extreme decelerations (upwards of $100 \mathrm{~g}$ 's).
\end{abstract}

Deployable aeroshells avoid the launch vehicle fairing diameter constraint by expanding to a larger diameter after the launch. Due to the potentially larger wetted area, deployable aeroshells achieve lower ballistic coefficients (well below $100 \mathrm{~kg} / \mathrm{m}^{2}$ ), and if they are flown at shallower flight path angles, the entry vehicle can access trajectories with far lower decelerations $\left(\sim 50-60 \mathrm{~g}\right.$ 's), peak heat fluxes $\left(\sim 400 \mathrm{~W} / \mathrm{cm}^{2}\right)$ and peak pressures. The structural and TPS mass of the shallow- $\gamma$, low- $\beta$ deployables are lower than their steep- $\gamma$, high- $\beta$ rigid aeroshell counterparts at larger diameters, contributing to lower areal densities and potentially higher payload mass fractions. For example, at large diameters, deployables may attain aeroshell areal densities of $10 \mathrm{~kg} / \mathrm{m}^{2}$ as opposed to $50 \mathrm{~kg} / \mathrm{m}^{2}$ for rigid aeroshells. However, the low $-\beta$, shallow $-\gamma$ paradigm also raises issues, such as the possibility of skip-out during entry. The shallow- $\gamma$ could also increase the landing footprint of the vehicle. Furthermore, the deployable entry systems may be flexible, so there could be fluid-structure interaction, especially in the high altitude, low-density regimes. The need for precision in guidance, navigation and control during entry also has to be better understood. This paper investigates some of the challenges facing the design of a shallow- $\gamma$, low- $\beta$ entry system.

\section{TAble of Contents}

1. INTRODUCTION 1

2. MOTIVATION

3. MASS SIZING ........................................................3

4. TRAJECTORY CHALLENGES ..............................5

5. HEATING AND AERODYNAMIC CHALLENGES....8

6. FUTURE WORK.................................................12

7. SUMMARY .................................................12

ACKNOWLEDGEMENTS ........................................12

REFERENCES ...............................................13

BIOGRAPHIES ...................................................

\section{INTRODUCTION}

Atmospheric probes and landers that have been sent to Venus in the past have relied on rigid aeroshells to protect the payloads during the initial entry into the planet's atmosphere. Although this type of vehicle has been used extensively and successfully for entry applications on other planets, Venus' thick atmosphere subjects the vehicles to large decelerations and heat fluxes.

Due to diameter constraints of launch vehicle fairings, rigid aeroshell vehicles typically have large ballistic coefficients $(\beta)$, which is a non-dimensional ratio of the vehicle's entry mass to the product of the drag coefficient $\left(\mathrm{C}_{\mathrm{D}}\right)$ and the projected reference area. Additionally, these vehicles have entered at steep flight path angles $(\gamma)$ to minimize the total heat load and the resulting Thermal Protection System (TPS) mass. But, the high heat fluxes seen in these trajectories also require the use of high-density materials, such as carbon phenolic, which decrease the payload mass capability of the vehicles. These ranges of the entry parameters lead to the high peak deceleration $\left(\mathrm{n}_{\max }\right)$ and large peak fluxes $\left(\mathrm{q}_{\max }\right)$, as is shown in Table 1 . Low- $\beta$ vehicles entering at shallow- $\gamma$ can reduce the peak deceleration and heat loadings. These vehicles can be deployed after launch or just prior to entry to increase the drag performance of the vehicle without the constraints of the launch vehicle's fairing diameter. 
Table 1. Past successful Venus entry missions. [1]-[6]

\begin{tabular}{|c|c|c|c|c|c|c|c|c|c|}
\hline Year & Mission & Nation & $\begin{array}{c}\boldsymbol{\beta} \\
\left(\mathbf{k g} / \mathbf{m}^{2}\right)\end{array}$ & $\begin{array}{c}\gamma \\
\text { (deg.) }\end{array}$ & $\begin{array}{l}V_{\text {entry }}^{i} \\
(\mathbf{k m} / \mathbf{s})\end{array}$ & Shape & $\begin{array}{l}\text { Dia. } \\
\text { (m) }\end{array}$ & $\begin{array}{c}\mathbf{n}_{\max } \\
\left(g^{\prime} \mathbf{s}\right)\end{array}$ & 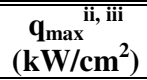 \\
\hline 1967 & Venera 4 & USSR & 519 & -78 & 10.7 & Sphere & 1.0 & 450 & 9.66 \\
\hline 1969 & Venera 5 & USSR & 549 & -62 to -65 & 11.2 & Sphere & 1.0 & $440-450$ & 13.5 \\
\hline 1969 & Venera 6 & USSR & 549 & -62 to -65 & 11.2 & Sphere & 1.0 & $440-450$ & 13.5 \\
\hline 1970 & Venera 7 & USSR & 677 & -60 to -70 & 11.2 & Circumellipsoid & 1.0 & $422-452$ & 17.0 \\
\hline 1972 & Venera 8 & USSR & 670 & -77 & 11.6 & Circumellipsoid & 1.0 & 500 & 30.0 \\
\hline 1975 & Venera 9 & USSR & 367 & -20.5 & 10.7 & Sphere & 2.4 & 150 & 3.04 \\
\hline 1975 & Venera 10 & USSR & 367 & -23 & 10.7 & Sphere & 2.4 & 170 & 3.37 \\
\hline 1978 & Pioneer-Venus-North & USA & 190 & -68.7 & 11.5 & 45 deg. Sphere-cone & 0.7653 & 487 & 10.6 \\
\hline 1978 & Pioneer-Venus-Night & USA & 190 & -41.5 & 11.5 & 45 deg. Sphere-cone & 0.7653 & 350 & 7.8 \\
\hline 1978 & Pioneer-Venus-Day & USA & 190 & -25.4 & 11.5 & 45 deg. Sphere-cone & 0.7653 & 219 & 5.2 \\
\hline 1978 & Pioneer-Venus-Large & USA & 188 & -32.4 & 11.5 & $45 \mathrm{deg}$. Sphere-cone & 1.4228 & 276 & 6.9 \\
\hline 1978 & Venera 11 & USSR & 376 & -18 to -21 & 11.2 & Sphere & 2.4 & $138-167$ & 4.35 \\
\hline 1978 & Venera 12 & USSR & 379 & -18 to -21 & 11.2 & Sphere & 2.4 & $138-167$ & 4.35 \\
\hline 1981 & Venera 13 & USSR & 387 & -18 to -21 & 11.2 & Sphere & 2.4 & $138-167$ & 4.35 \\
\hline 1981 & Venera 14 & USSR & 387 & -18 to -21 & 11.2 & Sphere & 2.4 & $138-167$ & 4.35 \\
\hline 1984 & Vega 1 & USSR & 412 & -18.23 & 10.7 & Sphere & 2.4 & 130 & 3.06 \\
\hline 1984 & Vega 2 & USSR & 412 & -19.08 & 10.8 & Sphere & 2.4 & 139 & 3.29 \\
\hline
\end{tabular}

${ }^{i}$ Entry velocities have been defined for a $200 \mathrm{~km}$ atmospheric interface at Venus

${ }^{\text {ii }}$ Trajectories were simulated from entry conditions and the simulations themselves were based on engineering estimates

iii The maximum heat flux is the combination of engineering estimates for cold-wall convective and radiative heat fluxes

The benefit of a lower ballistic coefficient is that the deceleration occurs at much higher altitudes and as a result the entry system experiences lower heating, pressure and heat load. Combining this with lower entry flight path angle provides many advantages over the rigid aeroshell systems. However, shallow- $\gamma$, low- $\beta$ systems have other design challenges. This paper will explore the motivation behind the design of shallow- $\gamma$, low- $\beta$ entry systems for Venus and discuss the issues facing the mass sizing, trajectory design and aerodynamic and aerothermodynamics of these systems.

\section{MOTIVATION}

\section{Previous Venus missions}

Between 1967 and 1984, the U.S. and U.S.S.R. sent many entry probes to Venus. Several of these probes successfully entered Venus' atmosphere on a direct entry from a hyperbolic orbit. Table 1 summarizes the past successful entry missions to Venus and lists their trajectory and performance parameters. The previous missions have all had ballistic coefficients higher than $100 \mathrm{~kg} / \mathrm{m}^{2}$, peak decelerations upwards of $100 \mathrm{~g}$ 's and peak total heat fluxes on the order of $1000 \mathrm{~W} / \mathrm{cm}^{2}$.

\section{Benefits of low ballistic coefficient entry systems}

The lowest ballistic coefficient of the past successful missions has been $188 \mathrm{~kg} / \mathrm{m}^{2}$. The shallowest flight path angle targeted has been around $-18 \mathrm{deg}$. and even these were associated with large ballistic coefficients $\left(379-412 \mathrm{~kg} / \mathrm{m}^{2}\right)$. Steep- $\gamma$, high- $\beta$ paradigms have constrained the entry trajectories to regimes of high peak deceleration and heat flux. The high deceleration loading and total heat load lead to increases in the structural and TPS mass fractions of the entry vehicle and degrades the payload mass fractions. However, decreasing the ballistic coefficient and the magnitude of the flight path angle can move the trajectories to regions with peak decelerations of the order of $10 \mathrm{~g}$ 's and heat fluxes lower than $100 \mathrm{~W} / \mathrm{cm}^{2}$, as shown in Figure 1 . The main drivers for direct entry into Venus are $\beta, \gamma$ and the entry velocity $\left(\mathrm{V}_{\text {entry }}\right)$. The entry velocity is primarily a function of the interplanetary trajectory, which can vary due to flight opportunities and for this figure, it is held constant at $11.5 \mathrm{~km} / \mathrm{s}$, which is similar to entry conditions for Pioneer-Venus. Mass and $C_{D}$ changed with ballistic coefficient while reference area was held constant.

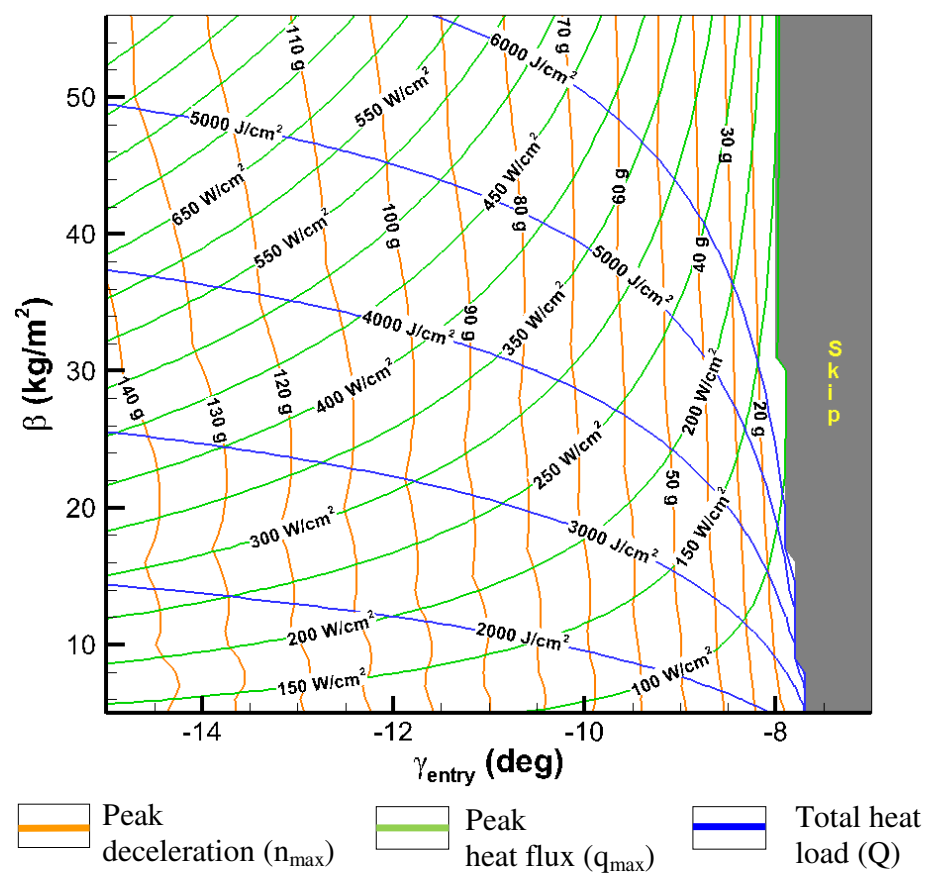

Figure 1. Entry vehicle's performance as a function of ballistic coefficient and entry flight path angle for direct entries at $V_{\text {entry }}=11.5 \mathrm{~km} / \mathrm{s}$ and nose radius of $2.5 \mathrm{~m}$. 
Note that the peak deceleration (orange curve) is as a strong function of the entry flight path angle and shallower angles lead to lower $\mathrm{n}_{\max }$. Also, peak heat flux (green curve) is lowered by a combination of lower ballistic coefficient and shallow flight path angle. The corresponding total heat loads (blue curve) are significantly lower than those for higher- $\beta$, steeper- $\gamma$ systems, despite the longer time of flight. This is due to the lower overall heat flux. Total heat load does actually increase when shallow flight angles are used for a fixed $\beta$, but an optimum design could be achieved by balancing the increase in Q (and hence TPS mass) and the reduction in $\mathrm{n}_{\max }$ (and structural mass).

Figure 1 also shows the vehicle skip-out boundary for a given ballistic coefficient. Skip-out in this paper is defined as the situation where the vehicle returns to the entry interface instead of continuing its descent towards the surface. Thus, there is a limit of the flight path angle that avoids skip-out for a given ballistic coefficient. This will be addressed in more detail in a later section. Aerocapture situations were not studied in this paper.

\section{Low ballistic coefficient entry system options}

Entry systems for Venus using a rigid aeroshell likely will not achieve ballistic coefficients much lower than 200 $\mathrm{kg} / \mathrm{m}^{2}$. In order to achieve a low ballistic coefficient for a given diameter and shape, either the payload mass has to be small or the entry system mass has to be reduced. One can increase the diameter, but for rigid aeroshells this cannot be greater than the current launch vehicle diameter limits (around $4.5 \mathrm{~m}$ ). Additionally, since radiative heat flux increases with diameter, reduction in the entry mass is limited for rigid aeroshells without new lightweight TPS and structural materials. Thus, for this study, low ballistic coefficient entry systems are synonymous with after-launch deployable systems.

The deployable entry systems may employ two types of mechanisms: Mechanically-deployed rigid systems; or inflatable deployable systems, also known as Inflatable Aerodynamic Decelerators (IAD). Mechanically deployed systems could have a forebody consisting of a flexible skin that is supported by ribs and struts (see Figure 2) or some other mechanism to deploy a load-bearing skin after launch. Inflatable deployables can have systems where pressurized gases inflate a forebody structure. Note that the torus is an integral shape for most inflatable structures. Research has been conducted on many different configurations of these inflatable entry systems and Figure 3 shows some of these concepts. Note that a rigid aeroshell is a component of the overall entry structure for some of these configurations. Onorbit assembly of low- $\beta$, rigid aeroshells has not been considered in this study.

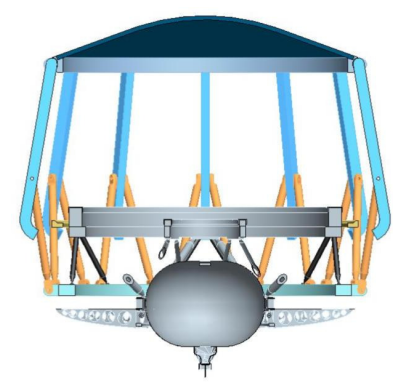

(a) Stowed for launch

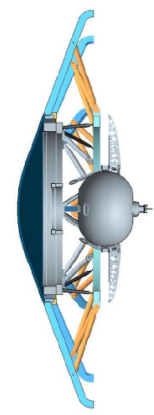

(b) Deployed for entry
Figure 2. Notional example of mechanical deployable entry systems. (Initial design seen in Ref. [7], above concept pictures from Bryan Yount and ADEPT team)

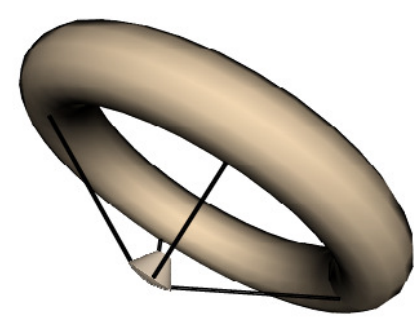

(a) Trailing torus

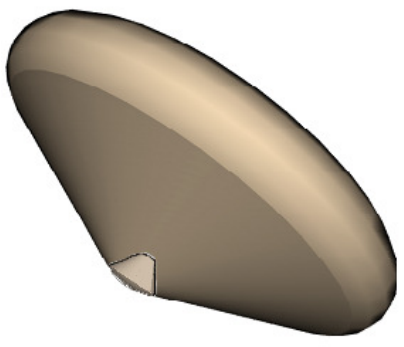

(c) Clamped torus

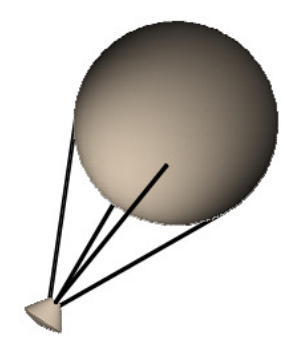

(b) Trailing ballute

\section{Figure 3. Notional examples of inflatable deployable entry systems. (Adapted from [8] and [9])}

\section{MASS SIZING}

One of the main motivations for lower ballistic coefficient vehicles with shallower entry flight path angles is the reduction in the structural and TPS mass possible from being in a more benign deceleration and heat flux region. This reduction could then be translated to more mass for scientific payload. However, it is expected that there will be some scalability concerns for deployable systems. Rigid aeroshells are expected to outperform deployables at certain sizes of entry vehicles and this study explores the mass sizing issues concerning shallow- $\gamma$, low- $\beta$ vehicles.

\section{Areal density comparison}

Rigid aeroshells and deployables of various sizes can be compared with each other using a parameter known as the areal density that is a ratio of the mass of the vehicle to the 
wetted area $\left(\mathrm{S}_{\mathrm{wetted}}\right)$. Specifically, the comparison is for the aeroshell areal density (Eq. 1), where the total "aeroshell" mass $\left(\mathrm{m}_{\text {aeroshell }}\right)$ is a combination of the structure and TPS masses. The difference between this "aeroshell" mass and the total entry system mass is defined as the "payload" mass, which can consist of scientific instruments, power equipment and the descent apparatus, such as parachutes, mortar deployment devices etc. An entry system that uses less structural and TPS mass will have a lower aeroshell mass and hence a smaller aeroshell areal density for a given payload size.

$$
\rho_{\text {areal }, \text { aeroshell }}=\frac{m_{\text {aeroshell }}}{S_{\text {wetted }}}=\frac{m_{\text {structure }}+m_{T P S}}{S_{\text {wetted }}}
$$

The comparison between areal densities of various entry systems is shown in Figure 4. The rigid aeroshell used is a $45 \mathrm{deg}$. sphere-cone and the deployables are $70 \mathrm{deg}$. spherecones. The $45 \mathrm{deg}$. sphere-cone is the only rigid aeroshell shape flown by the U.S. at Venus, while the 70 deg. spherecone model is the current shape being considered for the deployables due to payload capability and stability purpose. The rigid aeroshell structure and TPS mass calculations are done using historical relationships ([11]-[14]), the mechanical deployable masses are calculated using firstorder engineering sizing tools [13] and the IAD mass sizing is done for a stacked tori concept and based on the approach presented in Ref. [15]. This IAD sizing approach was used in the two recent NASA Entry, Descent and LandingSystem Analysis (EDL-SA) Mars mission studies [16]-[17]. The rigid aeroshell mass sizing stops at $3.5 \mathrm{~m}$ to avoid extrapolation from historical data, while the deployable mass sizing begins from $4 \mathrm{~m}$. Rigid aeroshells appear to be mass-efficient for small size vehicles (looking at Figure 5) and already have flight heritage; however, when the size of the vehicle needs to increase, rigid aeroshells cannot be used due to the launch vehicle fairing diameter limit and hence the deployables can be very effective substitutes.

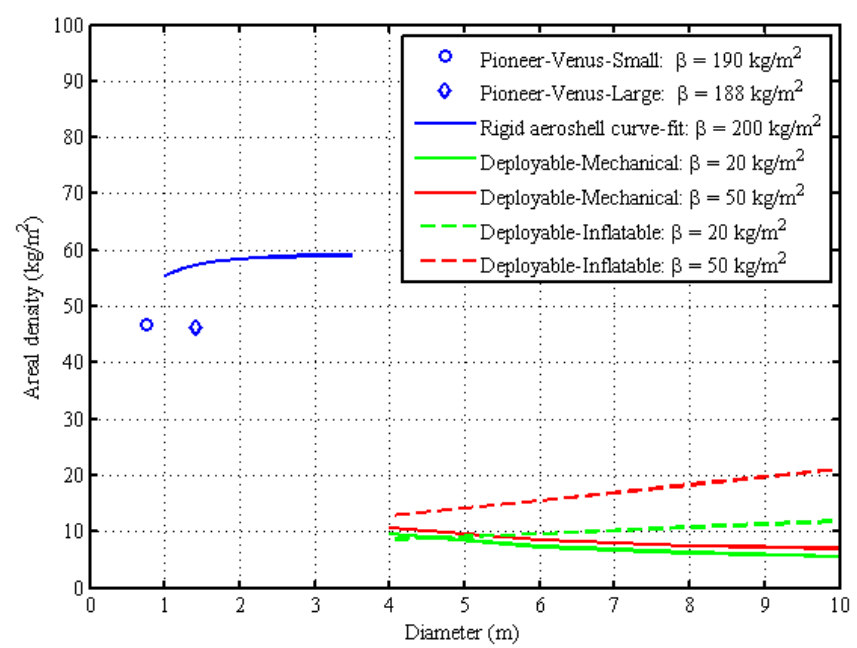

Figure 4. Aeroshell areal density comparison between rigid aeroshells and deployable entry vehicles of various sizes. Vehicle entry at $\gamma=-9 \mathrm{deg}$. and $V=11.5 \mathrm{~km} / \mathrm{s}$ at $200 \mathrm{~km}$ altitude on Venus.
The trends in the figure show that the aeroshell areal densities are lower for the deployables when compared to the rigid aeroshells at larger diameters. The areal density trends for the deployables at lower diameters are harder to estimate and may show higher areal densities than rigid aeroshells. However, since aeroshell areal density is the effective mass of the aeroshell per wetted area, the lower effective mass of a deployable frees up mass for the "payload," a fraction of which includes the science payload at larger diameter vehicles. It should be noted that since the tools used to generate the data for the deployables are not at very high fidelity, there remains some uncertainty in the estimated mass values. Also, the figure is not meant for comparison between the different types of deployables. Fabrication of IADs and mechanical deployables with smaller diameters and low dynamic pressures is challenging due to the material availability with relevant minimum thicknesses. Thus, there are too many uncertainties in the current modeling to make effective comparisons between the two types of deployables.

\section{Payload mass fraction comparison}

It is not surprising that the areal densities of the deployables were lower than the rigid aeroshell, since there was a large difference in ballistic coefficients between the two types of vehicles and the areal density formulation is similar to the definition of $\beta$. Additionally, there is also a large disparity in the entry and payload masses of the rigid aeroshell and the two deployables. Thus, a more even comparison of the payload capabilities of the rigid aeroshells and deployables can be done using payload mass fractions (ratio of payload mass to entry mass). Figure 5 shows this comparison.

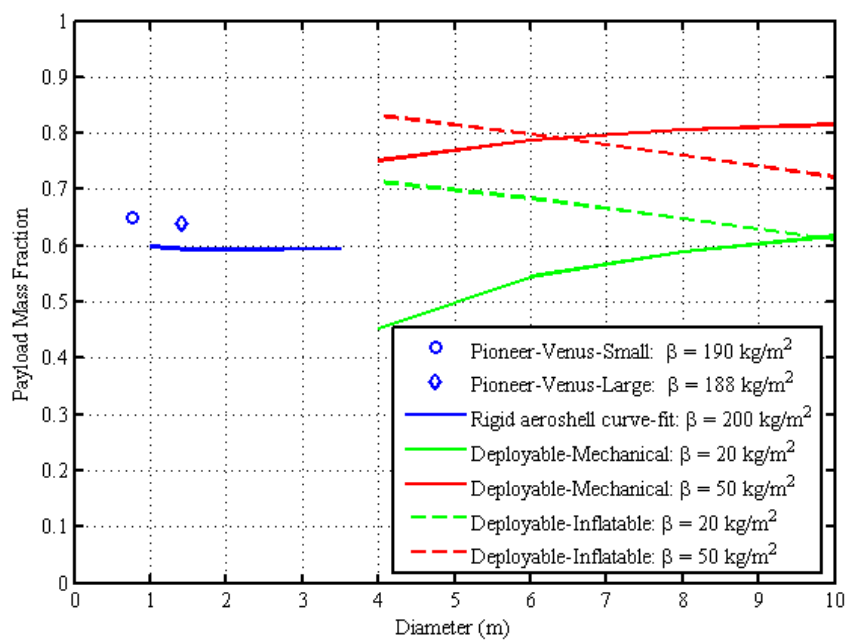

Figure 5. Payload mass fraction comparison between rigid aeroshells and deployable entry vehicles of various sizes. Vehicle entry at $\gamma=-9 \mathrm{deg}$. and $V=11.5 \mathrm{~km} / \mathrm{s}$ at $200 \mathrm{~km}$ altitude on Venus.

The payload mass fractions for the rigid aeroshell remain more or less constant, while the mass fractions of the deployables change with size. At larger vehicle diameters, the deployables seem to have high payload mass fractions. 
As expected, the advantage of deployables magnifies with increases in their wetted areas.

It might appear from Figure 5 that a high ballistic coefficient is desired for deployables due to a larger payload mass fraction. However, higher- $\beta$ systems, for a given diameter and entry $\gamma$, have higher entry masses, peak heat fluxes and total heat loads. The entry mass specifically is a huge problem because although one gets higher mass fraction efficiency with a high- $\beta$ system, the entry mass might become too exorbitant for Earth launch vehicle capabilities. Additionally, the higher deceleration loadings might also be undesirable for certain scientific payloads.

Although the payload mass fractions for the rigid aeroshells are $\sim 0.6$, this includes mass of the descent stage and other protective mass so that the actual mass fraction for science components will be much lower. Rigid aeroshells fly at a higher ballistic coefficients and steeper flight path angles and will have higher peak decelerations; thus, part of the "payload" mass will have to be used for structure to protect the actual science payload from these high decelerations. Pioneer Venus Large Probe's (PVLP) science payload mass fraction was only $\sim 9 \%$ [1]. Since shallow- $\gamma$, low- $\beta$ systems will have lower peak decelerations, it is expected a smaller portion of the "payload" mass will be used to protect the actual cargo.

\section{TRAJECTORY CHALLENGES}

Although shallow- $\gamma$, low- $\beta$ entries reduce deceleration and heat flux loadings, these entries also introduce some complications into the trajectories, such as possibility of skip-out or larger dispersions in trajectory footprint. This section explores these trajectory-related issues intrinsic to shallow- $\gamma$, low- $\beta$ entry systems.

\section{Skip-out}

As seen Figure 1, flying at shallow- $\gamma$ leaves open the possibility that the entry system could skip-out of the atmosphere if there are deviations from the nominal trajectory. Thus, when planning for a targeted shallow flight path angle, a margin has to be applied to avoid the possibility of the vehicle skipping-out. Skip-out in this case is defined as the situation when the vehicle returns to the entry interface (assumed to be $200 \mathrm{~km}$ altitude for Venus) after initially entering the atmosphere. The skip-out margin has to account for deviations from the nominal trajectory for various reasons. Mainly, the perturbations can be due to the atmospheric variations and interplanetary trajectory delivery errors. Science, mission and communication requirements could also limit the entry flight path angle that is allowed.

The sensitivity of the skip-out angle to atmospheric perturbation (especially density) is demonstrated in Figure 6. The graph shows the skip-out flight path angle (the steepest angle at which skip-out occurs) for various ballistic coefficients and randomly generated perturbed atmospheric density profiles. The randomly generated atmospheres were created using Venus Global Reference Atmospheric Model (Venus-GRAM) [10]. The range of variation of the skip-out angles for a given $\beta$ is about $0.05 \mathrm{deg}$. These variations must be taken into account when quantifying the skip-out margin. There is also sensitivity to ballistic coefficient as skip-out limit is at steeper angles for higher ballistic coefficients. Higher ballistic coefficient entries have more kinetic energy than their lower ballistic coefficient counterparts and do not decelerate enough in the low-density upper atmosphere at shallow flight path angles. Thus, the high- $\beta$ entries need steeper entry flight path angles to avoid skipping out.

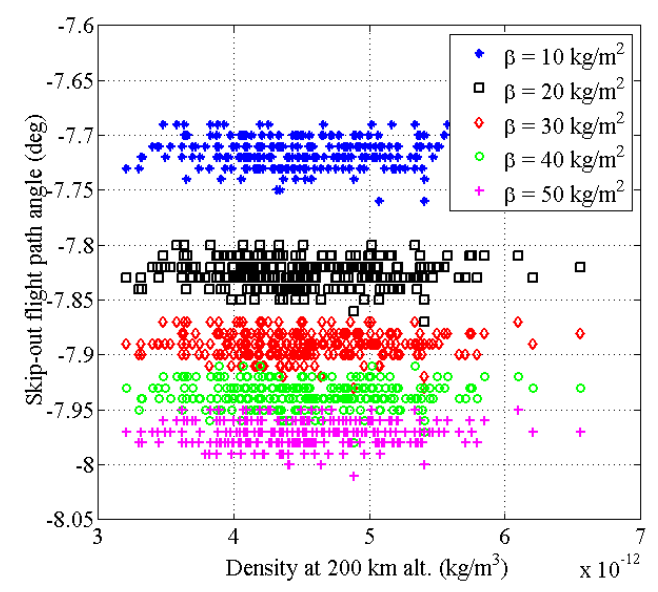

Figure 6. Skip-out flight path angle variation due to upper-atmosphere density variation.

The skip-out angle is also sensitive to the entry velocity. Entry velocity is a function of the interplanetary trajectory and the time of the flight opportunity.

Table 1 shows that the entry velocities for past Venus entry missions have been between 10.5 and $11.5 \mathrm{~km} / \mathrm{s}$, so Figure 7 shows the skip-out angle variation for entry velocities in that range. Entry trajectories with higher velocities have a higher kinetic energy and are more prone to skip-out; hence, they require a steeper entry flight path angle to avoid skip-out. This logic is the same as rationale for steeper skip-out angle limits for higher ballistic coefficient entries, as described earlier.

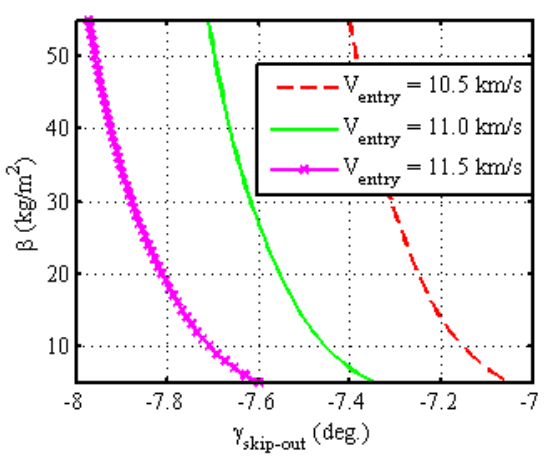

Figure 7. Skip-out angle variation due to entry velocity. Buoyancy effects

Venus' atmospheric density is thick when compared to the atmospheric densities of Earth and Mars. Thus, buoyancy 
force could potentially have an effect on the trajectories of entry systems, especially configurations with large volumes such as low ballistic coefficient entry systems. However, upon comparing the buoyancy force to the gravitational force (Figure 8), it can be seen that buoyancy force is not an important contributor during the entry trajectory in the upper atmosphere. Buoyancy effects might be important in the design of descent and landing systems that operate below $50 \mathrm{~km}$, but these effects are negligible when compared to gravity for regions where entry systems will be operated (i.e. altitudes greater than $50 \mathrm{~km}$ ).

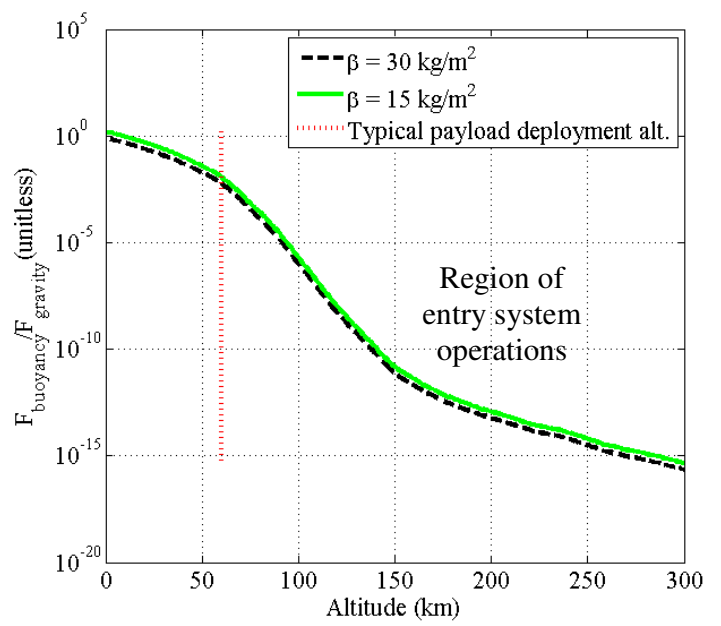

\section{Loading and footprint considerations}

The primary benefit of shallow- $\gamma$, low- $\beta$ entry vehicles at Venus is the reduced deceleration loading relative to the steep- $\gamma$, high- $\beta$ design paradigm. A potentially negative aspect of entering the atmosphere at a shallow flight path angle is reduced landing accuracy due to the propagation of atmospheric and aerodynamic uncertainties over a longer flight path. This section compares the deceleration profile and mid-atmosphere footprint of a nominal shallow- $\gamma$, low- $\beta$ entry with that of a steep- $\gamma$, high- $\beta$ entry similar to the PVLP. To shed light on this trade, a Monte Carlo trajectory analysis using the Program to Optimize Simulated Trajectories II (POSTII) is conducted per the nominal parameters and $3 \sigma$ dispersions in Table 2.

The entry vehicle will most likely deploy descent and landing phases when subsonic conditions are reached. Since this paper compares the performance of different types of entry vehicles, the "footprint" analysis is conducted when Mach 0.8 is reached by the perturbed trajectories. Flight path data below Mach 0.8 performed by the descent and landing stages has not been considered in this study. Results below compare the steep- $\gamma$, high- $\beta$ (PVLP) and shallow- $\gamma$, low- $\beta$ trajectory profiles (Figure 9 ) and sensed acceleration profiles (Figure 10).

Figure 8. Buoyancy force to gravitational force ratio as a function of altitude. Entry body is a $70 \mathrm{deg}$. sphere-cone.

Table 2. Parameters and assumptions for Monte Carlo trajectory analysis of a nominal shallow- $\gamma$, low- $\beta$ entry vehicle and a steep- $\gamma$, high- $\beta$ entry vehicle (PVLP-like).

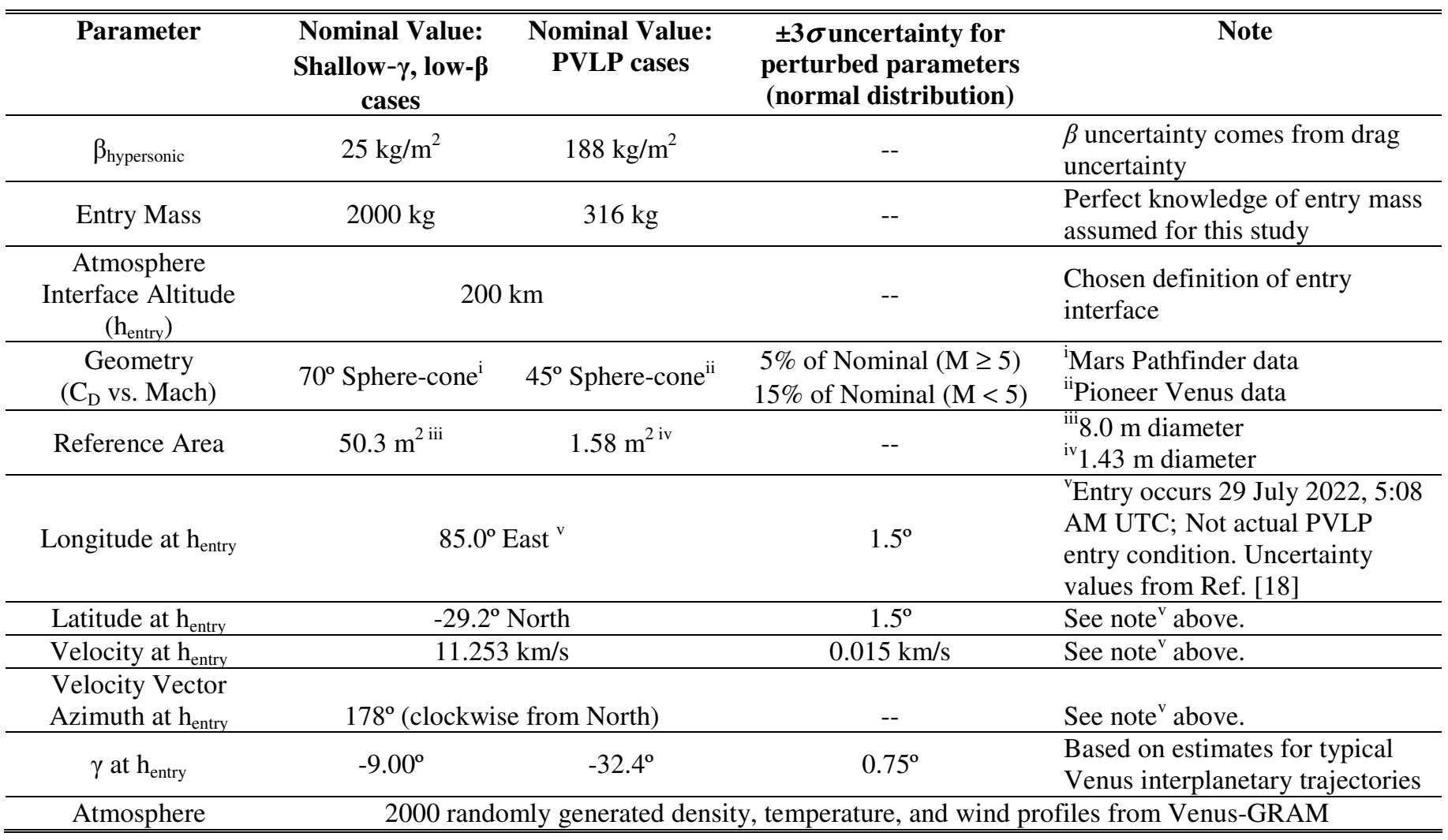




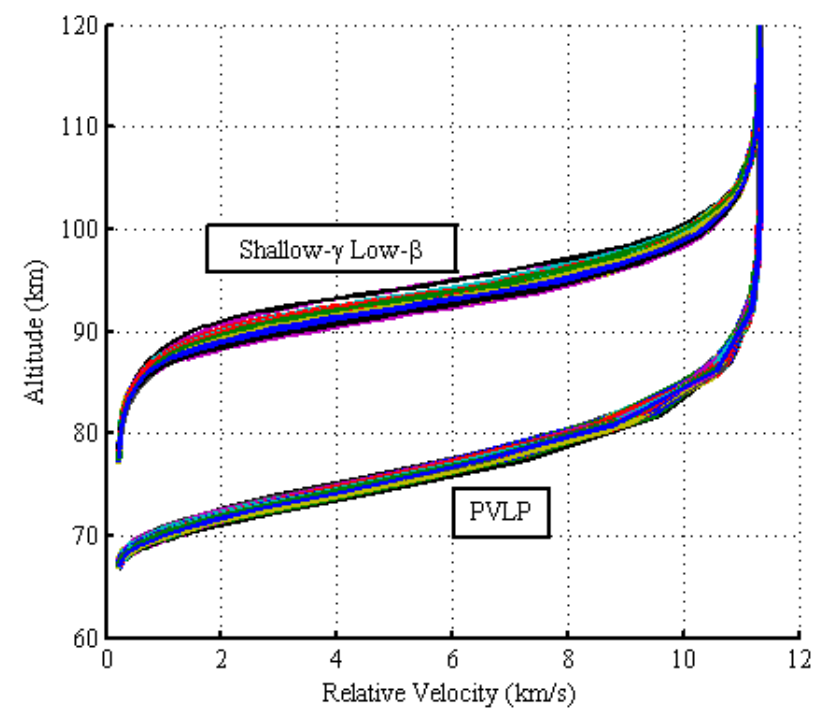

Figure 9. Dispersed trajectories (2000 cases) for PVLP and shallow- $\gamma$, low- $\beta$.

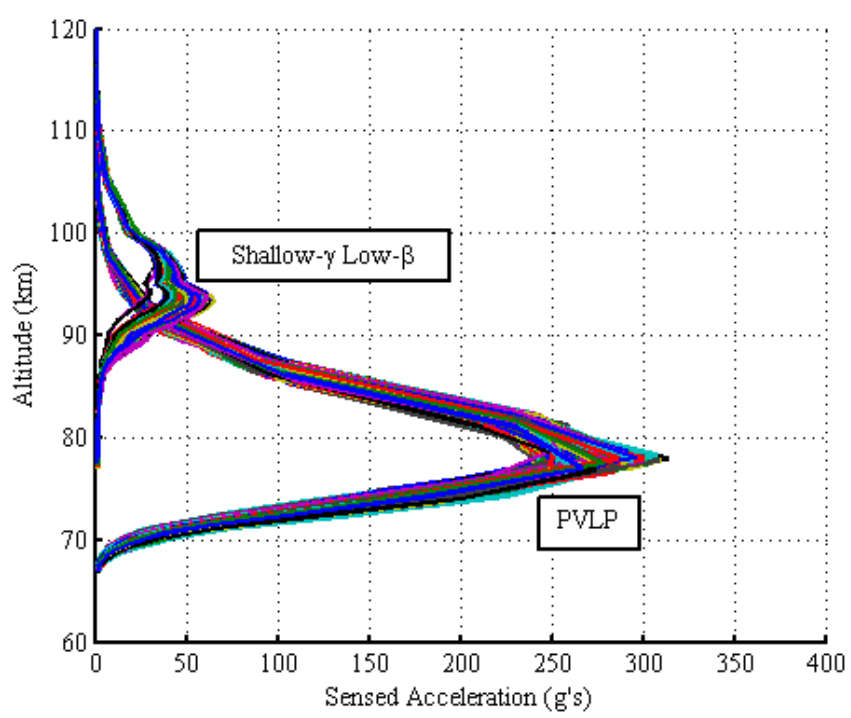

Figure 10. Deceleration loadings for PVLP and shallow$\gamma$, low- $\beta$ (2000 cases each).

The trajectory profiles show that the PVLP entry conditions cause the vehicle to dig deeper into the atmosphere and decelerate at a lower altitude (denser atmosphere). In contrast, the shallow- $\gamma$, low- $\beta$ vehicle begins decelerating about $15 \mathrm{~km}$ higher than the PVLP cases. Beginning deceleration at higher altitude extends the loading pulse over a longer period of time and reduces the instantaneous sensed acceleration substantially. The worst-case PVLP trajectory experienced $314 \mathrm{~g}$ 's of deceleration compared to $65 \mathrm{~g}$ 's for the worst-case shallow- $\gamma$, low- $\beta$ vehicle. While this improved loading environment is still severe, the low- $\beta$, shallow- $\gamma$ entry vehicle design provides for a comparatively more benign design environment for the scientific payload than the traditional Venus entry vehicle design paradigm.

Landing accuracy at Venus is driven by the planet's extreme winds. Equatorial and mid-latitude wind speeds can exceed
$100 \mathrm{~m} / \mathrm{s}$ above $60 \mathrm{~km}$ and gradually decrease to a calm breeze at the surface. Randomly generated wind profiles from Venus-GRAM [10] used in this trajectory analysis are shown in Figure 11. Note that subsonic flight is achieved near $70 \mathrm{~km}$ altitude for both cases. This implies that the magnitude and direction of the atmosphere-relative velocity vector is driven almost entirely by winds below this altitude and winds will be a dominant factor in landing dispersions. Additionally, most of the winds appear to move more East to West than North to South. So, final landing dispersions are expected to be more perturbed in the longitudinal direction by the winds.
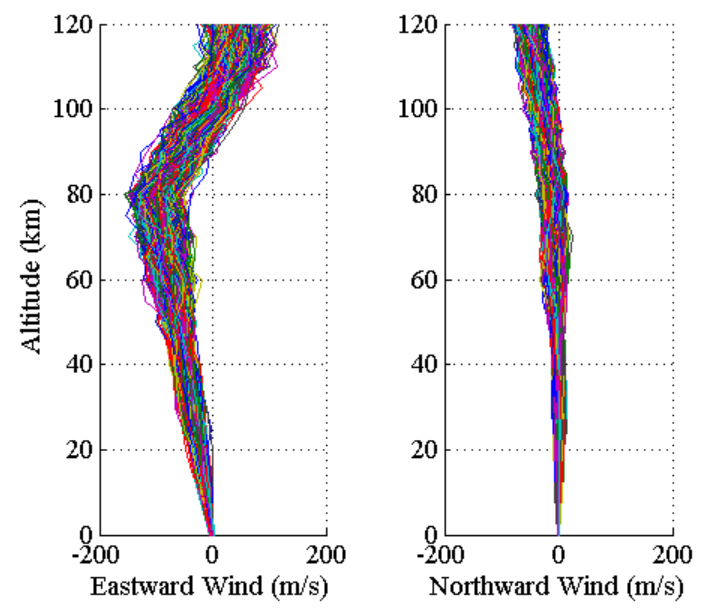

Figure 11. Wind profiles at the entry location randomly generated with Venus-GRAM.

Although the final landing dispersion for Venus will be very much affected by winds and the descent/landing vehicle configuration, it is informative to see whether the choice of a shallow- $\gamma$, low- $\beta$ vehicle for the entry phase adversely affects the timing of the EDL stages when compared to PVLP-type trajectories. The entry system's effect on the EDL trajectory can be studied at descent stage deployment location, which in this case is when Mach 0.8 is reached.

The coordinates of the entry vehicle when it has decelerated to Mach 0.8 for the PVLP cases and the shallow- $\gamma$, low- $\beta$ cases are shown in Figure 12 and Figure 13, respectively. Note that these trajectories have been propagated until the vehicle reaches Mach 0.8, so these trajectories did not end at the same altitude. However, all of them reached Mach 0.8 in the $60-80 \mathrm{~km}$ range. The $3 \sigma$-uncertainty ellipse is computed from the 2000 cases and is overlaid in red. The size and shape of this ellipse is driven by the propagation of atmospheric and aerodynamic uncertainties above $70 \mathrm{~km}$. Recall that below $70 \mathrm{~km}$ the motion of the entry vehicle is determined by wind, which mostly blow along lines of latitudes. As such, the longitude dispersions of $3.0^{\circ}$ seen for both entry vehicle paradigms will be increased by the wind velocity uncertainties in the lower atmosphere. 


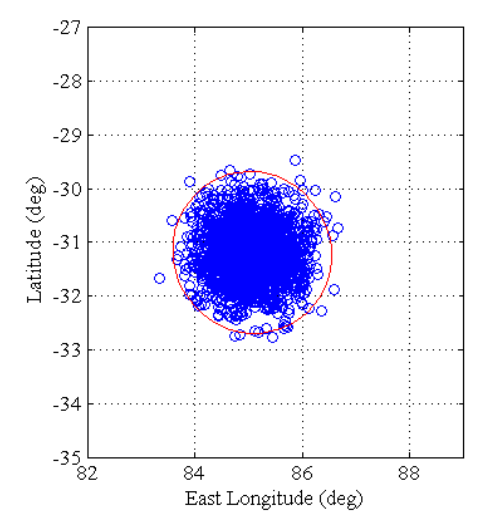

Figure 12. PVLP locations at Mach 0.8. The red ellipse

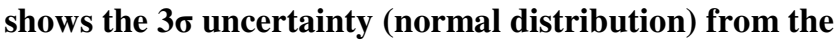
mean for the dispersed trajectories.

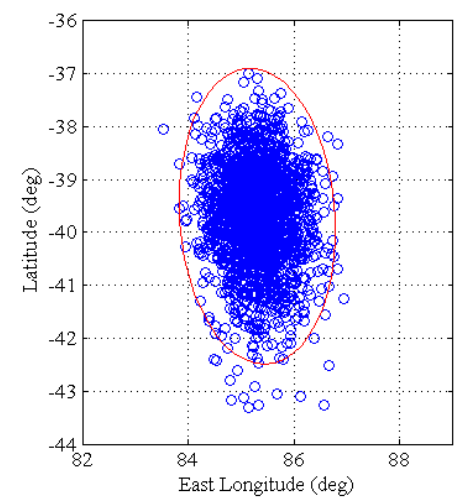

Figure 13. Shallow- $\gamma$, low- $\beta$ locations at Mach 0.8. The red ellipse shows the $3 \sigma$ uncertainty (normal distribution) from the mean for the dispersed trajectories.

The extended fight path of the shallow- $\gamma$, low- $\beta$ cases results in a $3 \sigma$ ellipse spanning 5.6 degrees of latitude, while the PVLP design results in a $3 \sigma$ ellipse spanning 3.0 degrees of latitude. Note that the entry velocity vector for this particular study points almost directly from North to South (azimuth of $178^{\circ}$ ), so a "footprint" latitude uncertainty of $5.6^{\circ}$ represents a worst-case scenario. There is some increase in the landing latitude uncertainty using the shallow- $\gamma$, low$\beta$ entry systems, but the increase is by only a few degrees. This implies that employing shallow- $\gamma$, low- $\beta$ technology at Venus will reduce the loading environment experienced by the scientific payload without significantly increasing the landing location error.

\section{HEATING AND AERODYNAMIC CHALLENGES}

This section will consider the challenges associated with the aerodynamics and heating of low- $\beta$, shallow- $\gamma$ deployables that can flex when under a load (static and dynamic), unlike rigid aeroshells. The specific calculations shown in this paper are for the mechanical deployable concept named Adaptive Deployable Entry ProjecT (ADEPT) and is shown in Figure 2, although IADs and other deployables also share many of the challenges discussed here.

\section{Aerothermal considerations}

The decelerator concept developed under ADEPT ([7], [19]) differs significantly from traditional rigid aeroshells and somewhat from other deployables, such as IADs. First, there is no metallic (or composite) shell structure to which the TPS is bonded; instead, the structural load is carried by a finite number of ribs in the ADEPT concept. Additionally, the flexible carbon cloth draped over the ribs serves the dual purpose of a continuous structure and a thermal protection system. Cloth woven from carbon fiber has good structural strength and has the ability to re-radiate from both front and back sides, which allows management of aerodynamic heating experienced during high-speed $\left(\mathrm{V}_{\text {entry }} \sim 11.5 \mathrm{~km} / \mathrm{s}\right)$ entry into Venus' atmosphere. Furthermore, a combination of flexible ablative materials (still in the early stages of technology development) and carbon cloth might provide a hypersonic decelerator system that is capable of withstanding high heat fluxes without the need to make the decelerator diameter very large (by reducing the entry ballistic coefficient and hence aerodynamic heating). The ADEPT decelerators may range in sizes from $4 \mathrm{~m}$ to $10 \mathrm{~m}$ in diameter for Venus entry and are much larger than the rigid aeroshells that have been used in the past U.S. missions to Venus (PVLP was only $1.4 \mathrm{~m}$ in diameter).

However, ADEPT can also flex under loads and that can enhance aerothermal effects on the body. This concern is also shared by other deployables, such as IADs. The objective of this section is to explore the aerothermal issues using currently available modeling and simulation tools.

Modeling and simulation tools, such as Data-Parallel Line Relaxation Methods (DPLR) [20] for flow field calculations and the Nonequilibrium Air Radiation (NEQAIR) Program [21] for radiation computations, are currently employed in the design of rigid aeroshells (for atmospheric entry into any planet) and are quite mature. Application of such tools to "smooth shapes", i.e., initial shapes without any deflections, provides baseline estimates of the pressure, shear and heat flux environments. From these baseline estimates, one can carry out focused trade studies to highlight areas of concern for flexible, deployable decelerators.

For the purposes of discussion in the present paper, two masses $-1000 \mathrm{~kg}$ and $2000 \mathrm{~kg}$ - are considered for the entry vehicle. Furthermore, the entry velocity is set to be 11.5 $\mathrm{km} / \mathrm{s}$ at $200 \mathrm{~km}$ Venus altitude and several sphere-cone configurations with cone angles ranging from $45^{\circ}$ to $70^{\circ}$ and diameters ranging from $6 \mathrm{~m}$ to $10 \mathrm{~m}$ are considered. In all cases, the entry $\gamma$ is set to $-8.25^{\circ}$ (sufficiently away from the skip boundary). DPLR v4.02.2 has been used with a 16species gas model that represents shock-layer thermochemical nonequilibrium and NEQAIR 2009 v7 has been used for radiation computations. Radiative processes are assumed to be decoupled from the flow field and radiative heating is computed a posteriori using predicted shock-layer temperatures and species number densities. 
The entry vehicles have low ballistic coefficients, so the vehicle should slow down rapidly in the upper atmosphere where the density is low. Due to small freestream densities, the expected heating on the smooth configurations will be small. Figure 14 shows centerline distributions of cold-wall $\left(\mathrm{T}_{\mathrm{w}}=400 \mathrm{~K}\right.$, fully catalytic) convective heat flux (at the peak total heating point on the trajectory) and pressure (at the peak dynamic pressure point on the trajectory) for two smooth, sphere-cone geometries $\left(45^{\circ}\right.$ and $\left.70^{\circ}\right)$ for a $6 \mathrm{~m}$ diameter decelerator $\left(m_{\text {entry }}=1000 \mathrm{~kg}\right)$. Figure 15 shows the same paramters when the decelerator has a $10 \mathrm{~m}$ diameter $\left(\mathrm{m}_{\text {entry }}=2000 \mathrm{~kg}\right)$. The larger diameter leads to a larger nose radius and hence lower peak heat flux.

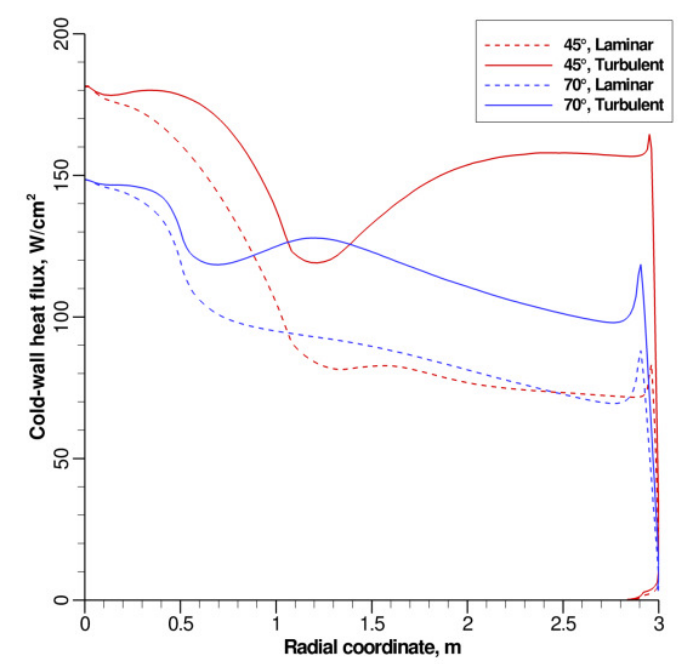

(a) Cold-wall convective heat flux at peak total heating

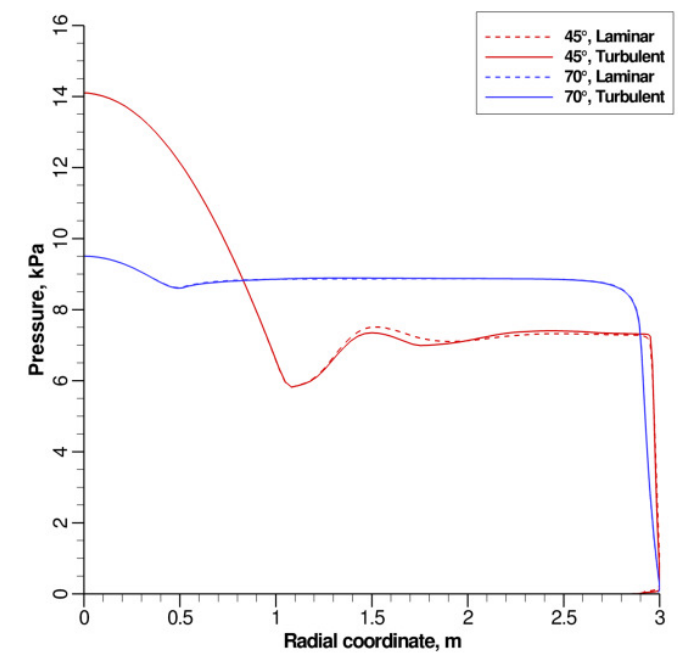

(b) Surface pressure at peak dynamic pressure

Figure 14. Centerline distributions of cold-wall $\left(T_{\mathrm{w}}=400\right.$ K) convective heat flux and pressure for $1000 \mathrm{~kg}, 6 \mathrm{~m}$ diameter ADEPT geometries.

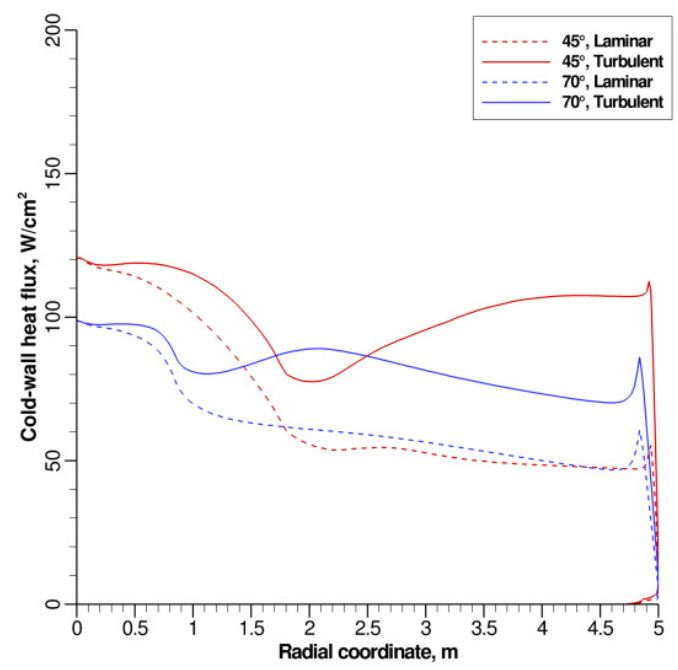

(a) Cold-wall convective heat flux at peak total heating

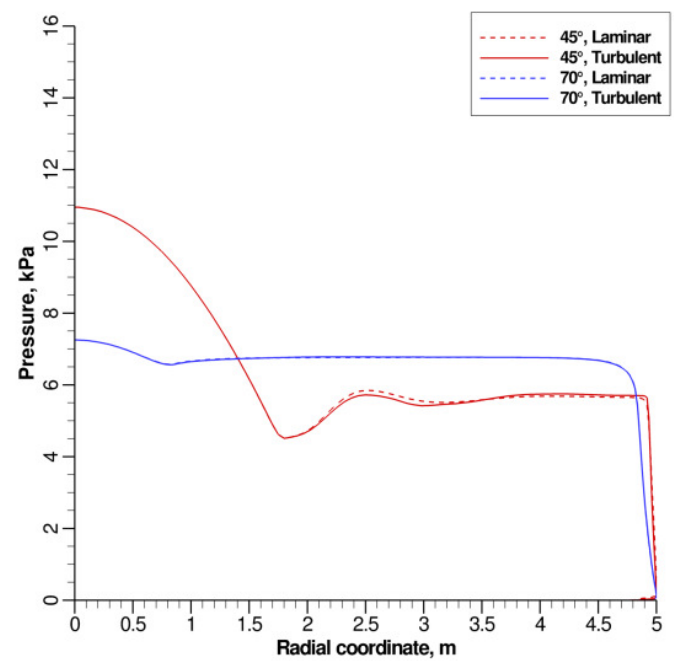

(b) Surface pressure at peak dynamic pressure

Figure 15. Centerline distributions of cold-wall $\left(T_{\mathrm{w}}=400\right.$ K) convective heat flux and pressure for $2000 \mathrm{~kg}, 10 \mathrm{~m}$ diameter ADEPT geometries.

A few points from the two figures (Figure 14 and Figure 15): (1) the cold-wall convective heat flux, even with consideration of a turbulent shear layers, does not exceed $200 \mathrm{~W} / \mathrm{cm}^{2}$; and (2) the impact pressure does not exceed $0.14 \mathrm{~atm}$. It should be noted that the magnitude of the convective heat flux on flanks of the sphere-cones are somewhat conservative. If the surface were to be treated as a hot wall, the heat flux would be reduced, and reduced even further if the surface were allowed to re-radiate from sides, front and back. The analysis thus far does not consider shock-layer radiation.

The next step is to develop configurations that are closer to those envisaged for flight. Figure 16 shows a conceptual 12rib, $8 \mathrm{~m}$ diameter decelerator geometry enclosed within the defining surface (translucent cyan-colored surface) of a $70^{\circ}$ sphere-cone. Unlike rigid aeroshells with a rigid, uniform surface, the deployables like ADEPT will have a flexible surface for the forebody, such as flexible carbon cloth that is 
stretched between ribs. This creates a decrease in the projected area relative to the smooth shape and leads to a slightly higher ballistic coefficient than the equivalent smooth sphere-cone. In this simulation, ribs are idealized as sharp ridges and the carbon cloth drawn across the ribs are flat surfaces. One should expect high heating at the sharp ridges, and some reduction over the acreage because of the lack of curvature in the surface. Other deployables, such as IAD's, are expected to have similar issues.

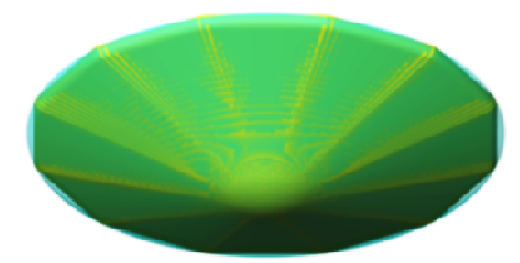

Figure 16. A conceptual 12-rib, $8 \mathrm{~m}$ diameter ADEPT geometry is shown encapsulated inside a smooth $70^{\circ}$ sphere-cone geometry (translucent cyan-colored surface). The surfaces between ribs (idealized as sharp ridges) have neither streamwise nor circumferential curvature.

Contours of cold-wall turbulent convective heat flux (at the peak total heating point on the trajectory) and pressure (at the peak dynamic pressure point on the trajectory) are shown in Figure 17. Elevated heating levels on the ridges (representative of ribs) can be clearly seen.

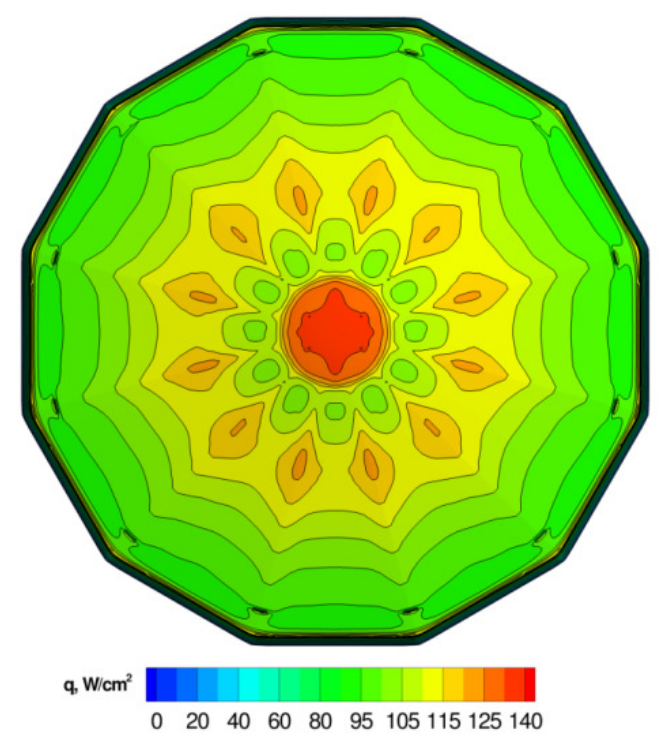

(a) Turbulent, convective heat flux $\left(\mathrm{W} / \mathrm{cm}^{2}\right)$ distribution at peak heating

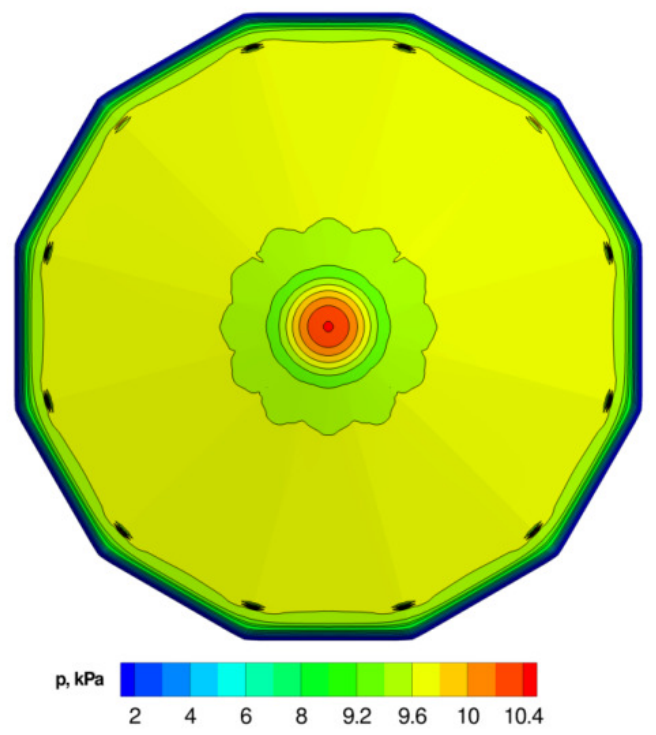

(b) Pressure (kPa) distribution at peak dynamic pressure

Figure 17. Surface distributions of cold-wall $\left(T_{\mathrm{w}}=\mathbf{4 0 0}\right.$

K) turbulent, convective heat flux [at peak total heating on the trajectory] and pressure [at peak dynamic pressure on the trajectory] for $2000 \mathrm{~kg}, 8 \mathrm{~m}$ diameter, 12-rib ADEPT geometries (based on a $70^{\circ}$ sphere-cone).

Centerline distributions of pressure and turbulent convective heat flux at two points - peak total heating and peak dynamic pressure - along the flight trajectory are shown in Figure 18. For a small number of points distributed over the centerline of the decelerator, radiative heating computations are performed using NEQAIR. The radiative heat flux values at the peak total heating point on the trajectory are shown as closed symbols in the figure. Total heat flux is a combination of the radiative and convective heat fluxes. Note that radiative heating is roughly $40 \%$ to $55 \%$ larger than convective heat flux. The reasons for this difference in heating are: (1) the size of the decelerator - a large subsonic bubble implies high radiation, and (2) the low freestream density, which enhances nonequilibrium radiation. Clearly, accurate characterization of nonequilibrium radiation from the shock layer is required in the future.

The total heat flux (sum of convective and radiative heating) is roughly $400 \mathrm{~W} / \mathrm{cm}^{2}$ and the impact pressure does not exceed 0.14 atm. Both these bounding values can be achieved in existing ground-test facilities such as arc jets at NASA Ames Research Center [22]. 


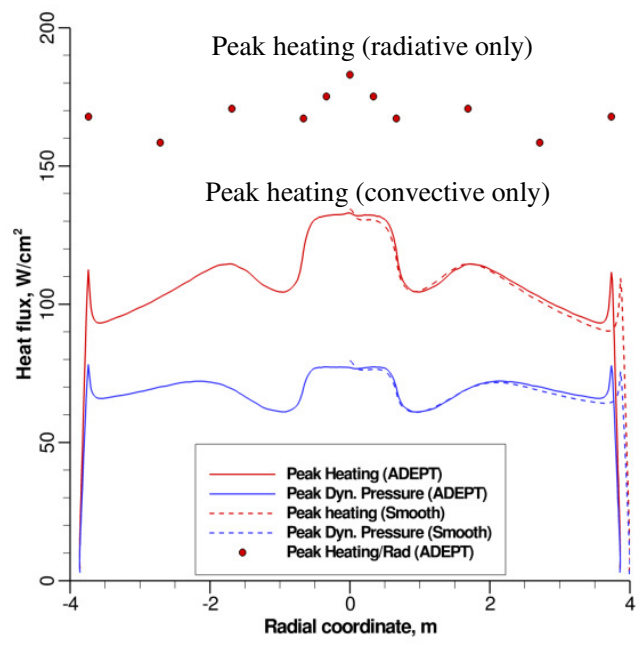

(a) Heat flux at two trajectory points

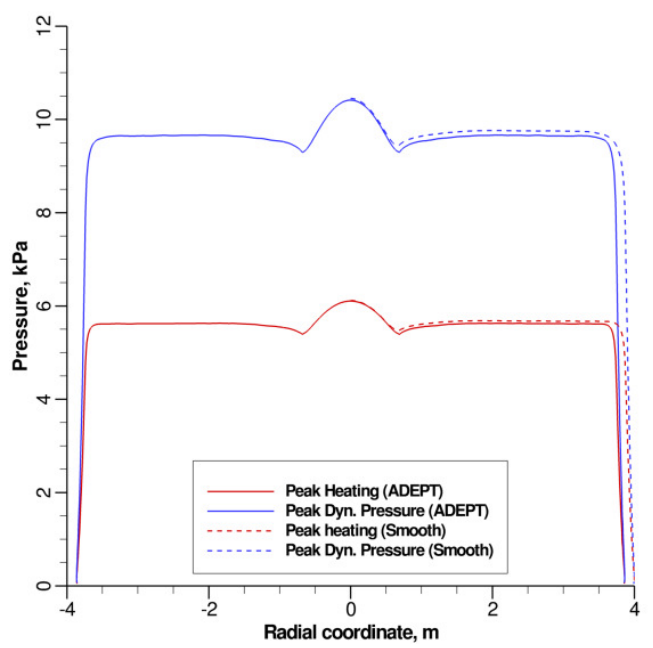

(b) Pressure distribution at two trajectory points

Figure 18. Centerline distributions of cold-wall $\left(T_{w}=400\right.$ K) turbulent, convective heat flux and pressure at two points - peak total heating and peak dynamic pressure along the trajectory for a 12 -rib, $8 \mathrm{~m}$ diameter, $\mathbf{7 0}^{\circ}$ sphere-cone ADEPT.

The aerothermal simulations that were done with cold wall assumption are valid for both rigid and inflatable deployables. When specifically considering ADEPT, which can radiate from both front and back, the effective heat flux estimation needs to include boundary conditions that permit re-radiation from the back and front and not just cold-wall heating. Proper modeling of re-radiation from both sides of the carbon cloth will require integration of a thermal response model into the flow simulations so that the thermal gradient through the cloth can be captured accurately. Other issues not considered in the simulations are the roughness and permeability of the carbon cloth. The former, if large enough, could enhance turbulence heating, and the latter could serve as a mechanism to bleed off small portions of the boundary layer, thereby bringing the boundary-layer edge closer to the surface and enhancing convective heating.
All the analyses thus far have focused on static configurations, i.e., the configuration that do not flex under imposed pressure loads. A loosely-coupled (iterative) approach was chosen for the precursor program to ADEPT to study the flexible, mechanical deployable shape [7]. In this approach, the predicted pressure loads were passed on to a structural analysis program, which then returned a deflected shape. Flow field analysis was performed on the deflected shape. Then structural analysis was performed once more with the new loads. This process was continued until change in deflections between two successive iterations was within some prescribed tolerance. A variation of this method has to be applied to the current configuration in the future. Yet, simply comparing aerothermal results between a smooth and a non-smooth deployable shape has raised issues.

\section{Aerodynamic considerations}

Having established the baseline estimates of aerothermal environments, the aerodynamics of the configuration need to be considered. There are three aspects to the aerodynamic problem: (1) static, which deals with placement of the center of gravity of the system and the sensitivity of this location due to static flexural loads; (2) dynamic, which deals with pitching/yawing motion of a flexing structure and the stability of the vehicle; and (3) the response of the carbon cloth to aeroacoustic loads (primarily from vortex shedding at supersonic and subsonic freestream Mach numbers).

Modern CFD tools will be able to address the first challenge easier than the other two items listed above. For example, Figure 19 shows the effect of center of gravity location on static stability $\left(\mathrm{C}_{\mathrm{M} \alpha}\right.$, derivative of the moment coefficient with respect to angle of attack) and payload mass availability for the ADEPT concept. However, the dynamic stability and fluid-structure interaction challenges may require not only high fidelity CFD simulation but also testing. These are beyond the scope of this paper, although they are recognized here as significant challenges. Figure 19 demonstrates that from the standpoint of static stability one would like to place the center of gravity near the nose of the vehicle, but the realities of packing efficiency, geometry of the vehicle and structural loads might dictate something else. The structural mass needed to withstand the peak deceleration and pressure loadings vary according to the placement of the center of gravity and the ensuing loading geometry. The payload mass (using the definition from the mass sizing section) available from this vehicle configuration seems to maximize near the maximum diameter of the vehicle although this means some loss in static margin. This trade between payload mass and stability will be crucial for any type of low- $\beta$ system. 


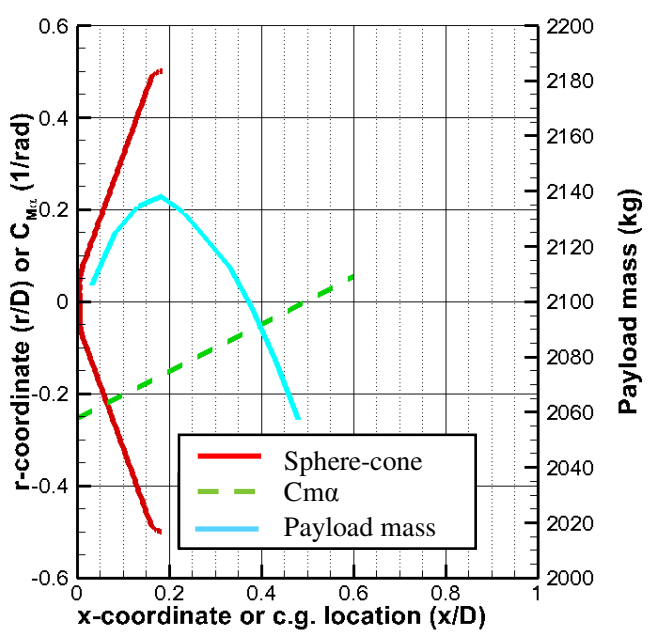

Figure 19. Effect of the center of gravity position (aft from nose) on static stability and payload mass for 70 deg. sphere-cone mechanical deployable concept with $\beta$ $=20 \mathrm{~kg} / \mathrm{m}^{2}$. Vehicle assumed to have $10 \mathrm{~m}$ dia. and entered at $\gamma=-9 \mathrm{deg}$. and $V=11.5 \mathrm{~km} / \mathrm{s}(200 \mathrm{~km})$ altitude into Venus' atmosphere.

\section{FUTURE WORK}

This paper highlighted the advantages of a low ballistic coefficient entry system at shallow entry flight path angles. However, further work in the following areas is still required to refine these concepts for use on Venus or other planetary bodies. (1) A descent stage deployment mechanism has to be developed that can create enough separation between a low- $\beta$ jettison stage and a relatively high- $\beta$ payload to avoid re-contact (2) Entry and descent stage designs have to account for the large wind drift due to the relative large wind speeds at mid-altitudes of Venus expected speed of the entry vehicles (3) One has to explore the aerodynamic characteristics of these vehicles in more detail, especially their behavior in pitch and yaw, due to the flexible nature of the deployables and large diameters required to achieve low enough ballistic coefficients. (4) Accurate characterization of nonequilibrium radiation from the shock layer is required due to the presence of nonnegligible radiative heating for low- $\beta$, shallow- $\gamma$ trajectories for Venus. (5) Finite element analysis has to be conducted to verify the design of the structure and payload bearing mechanisms in more detail.

There are also some program specific issues for each type of deployable. The design of the structure of IADs, especially at small diameters, can be an issue due to manufacturing constraints and material availability. Hypersonic IADs have been sized for around $20 \mathrm{~m}$ diameter for conceptual Mars missions, yet scaling above this size might lead to issues not yet studied. In the case of the ADEPT concept, one needs to study the torsional rigidity of the structure further since the simple rib/cloth design might not support high torque loads, leading to an increase in the structural mass needed to prevent twisting of the ribs.

\section{SUMMARY}

Low ballistic coefficient entry systems entering at shallow flight path angles on Venus can provide more benign entry conditions than previous paradigms using rigid aeroshell technologies. The lower peak decelerations, heat loads and fluxes may translate into lower structural and TPS masses for a range of scientific payloads. The advantages over rigid aeroshells are more pronounced when the diameters of the deployable bodies are increased, leading to a larger wetted area, lower areal density and higher payload mass fraction. However, the shallow- $\gamma$ opens the possibilities of skip-out during entry; thus, a skip-out margin has to be defined based on deviations from the nominal due to atmospheric perturbations or interplanetary trajectory delivery errors. The typically longer flight path of the shallow- $\gamma$, low- $\beta$ vehicle also introduces some dispersion in the trajectories of these vehicles when compared to trajectories of rigid aeroshells. The largest landing dispersions would be caused by the descent and landing stages rather than the entry stages. Also, since deployables are flexible, the structure will deflect from a smooth surface under pressure loading and can create augmented heating regions near these deflections. Additionally, in the Venusian atmosphere, nonequilibrium radiation could be enhanced, especially since the deployables will have large diameters (and nose radii). Finally, there are still some unresolved issues with both static and dynamic stability of these vehicles, especially since the flexible body will interact with pressure loadings.

\section{ACKNOWLEDGEMENTS}

Several people at various NASA centers supported the work presented in this paper. The authors would like to thank the members of the ADEPT team at NASA Ames Research Center, specifically Paul Wercinski, Kenneth Hamm, Alberto Makino, Ian Fernandez and Bryan Yount. Jamshid Samareh from NASA Langley Research Center provided calculations for mass sizing of IADs on short notice. The authors would also like to thank Greg Marr and David R. Williams of NASA Goddard Space Flight Center. Greg provided information about typical interplanetary trajectories to Venus and other science goals for Venus, while David gave valuable information about previous missions to Venus. The authors also thank David Saunders (ERC, Inc.) for some of the computations of the flow fields for the $70^{\circ}$ sphere-cone geometries. One of the co-authors, Dinesh Prabhu (ERC, Inc.), was supported by Contract NNA10DE12C from the Entry Systems and Technology Division at NASA Ames Research Center. Finally, the authors thank David Hash from NASA Ames, who provided the opportunity for the primary author to get involved in this project and Bobby Braun at Georgia Tech for providing inputs for this paper. 


\section{REFERENCES}

[1] "Planetary Mission Entry Vehicles: Quick Reference Guide," Version 3.0, NASA SP-2006-3401, 2006.

[2] Johnson, N.L., Handbook of Soviet Lunar and Planetary Exploration, Volume 47, Science and Technology Series, American Astronautical Society Publications, San Diego, CA, 1979.

[3] Reese, D.E. and Swan, P.R., "Venera 4 Probes Atmosphere of Venus," Science, Vol. 159, No. 3820, March, 1968, pp. 1228-1230.

[4] Marov, M.Y., "Venus: A Perspective at the Beginning of Planetary Exploration," Icarus, Vol. 16, 1972, pp. 415461.

[5] Harvey, B. The New Russian Space Programme: From Competition to Collaboration, John Wiley \& Sons, Chichester, England, 1996.

[6] Ball, A.J., Garrym, J.R.C., Lorenz, R.O., Kerzhanovich, V.V., Planetary Landers and Entry Probes, Cambridge University Press, New York, NY, 2007.

[7] Venkatapathy, E., et. al., "Adaptive Deployable Entry and Placement Technology (ADEPT): A Feasibility Study for Human Missions to Mars," 21st AIAA Aerodynamic Decelerator Systems Technology Conference and Seminar, Dublin, Ireland, AIAA Paper No. 2011-2608, 2011.

[8] Clark, I.G., Braun, R.D., Theisinger, J., Wells, G., "An Evaluation of Ballute Entry Systems for Lunar Return Missions," AIAA Atmospheric Flight Mechanics Conference and Exhibit, Keystone, CA, AIAA Paper No. 2006-6276, 2006.

[9] Hughes, S.J. Cheatwood, F.M., Dillman, R.A., Wright, H.S., DelCorso, J.A. and Calomino, A.M, "Hypersonic Inflatable Aerodynamic Decelerator (HIAD) Technology Development Overview," $21^{\text {st }}$ AIAA Aerodynamic Decelerator Systems Technology Conference and Seminar, AIAA Paper No. 2011-2524, 2011.

[10] Venus Global Reference Atmospheric Model (VenusGRAM 2005 Rel. Oct 2009), NASA Marshall Space Flight Center, Environments Group, EV13.

[11] Heineman, W., "Design Mass Properties II: Mass Estimating and Forecasting for Aerospace Vehicles Based on Historical Data," NASA JSC-26098, 1994.

[12] Bienstock, B.J., "Pioneer Venus and Galileo Entry Probe Heritage," International Workshop on Planetary Atmospheric Entry and Descent Trajectory Analysis and Science, Lisbon, Portugal, 2003.
[13] Givens, J., "Pioneer Venus \& Galileo Probe Development Comparison/Assessment," 6th International Planetary Probe Workshop, Atlanta, GA, 2008.

[14] Laub, B. and Venkatapathy, E., "Thermal Protection System Technology and Facility Needs for Demanding Future Planetary Missions," International Workshop on Planetary Probe Atmospheric Entry and Descent Trajectory Analysis and Science Proceedings, Lisbon, Portugal, Oct. 2003.

[15] Samareh, J. A., "Dimensionless Parameters for Estimating Mass of Inflatable Aerodynamic Decelerators," 8th Annual International Planetary Probe Workshop (IPPW-8), Portsmouth, VA, June 6-10, 2011.

[16] Dwyer Cianciolo, et. al., "Entry, Descent and Landing Systems Analysis Study: Phase 1 Report," NASA/TM2010-216720, March 2010.

[17] Dwyer Ciancolo, et. al.," Entry, Descent and Landing Systems Analysis Study: Phase 2 Report on Exploration Feed-Forward Systems," NASA-TM-2011-217055, March 2011.

[18] Findlay, J.T., Kelly, G.M., “A Recommended Entry Reconstruction Process for the Pioneer Venus MultiProbe Mission," NASA CR-158962, 1978.

[19] Venkatapathy, E., Allen, G., Prabhu, D., and White, T., "Going Beyond Rigid Aeroshells: Enabling Venus and Outer-Planet in situ Science Missions with Deployables," 8th Annual International Planetary Probe Workshop (IPPW-8), Portsmouth, VA, June 6-10, 2011.

[20] Wright, M.J., White, T., and Mangini, N., "Data-Parallel Line Relaxation Methods (DPLR) Code User Manual Acadia-Version 4.01.1," NASA/TM-2009-215388, October 2009.

[21] Whiting, E. E., Park, C., Liu, Y., Arnold, J.O., and Paterson, J.A., "NEQAIR96, Nonequilibrium and Equilibrium Radiative Transport and Spectra Program: User's Manual," NASA RP-1389, NASA, December 1996.

[22] Space Technology Division, NASA Ames Research Center (2011). Thermophysics Facilities Branch Fact Sheet [Online]. Available: http://thermophysics.arc.nasa.gov/fact_sheets/ArcJet $\% 20$ Fact $\% 20$ She et.pdf 


\section{BIOGRAPHIES}

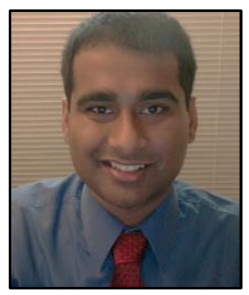

Soumyo Dutta is a graduate research assistant at the Georgia Institute of Technology. He has interned at the NASA Jet Propulsion Laboratory, Langley Research Center, Ames Research Center and Charles $S$. Draper Laboratory. He received a B.S. in Mechanical Engineering from the Univ. of Tennessee and a M.S. in Aerospace Engineering from Georgia Tech and is currently pursuing his Ph.D. His research interest is in the area of parameter estimation for EDL vehicles, especially reconstructing trajectory, atmosphere and aerodynamic properties of entry vehicles from on-board flight sensors. He is advised by Dr. Robert Braun.

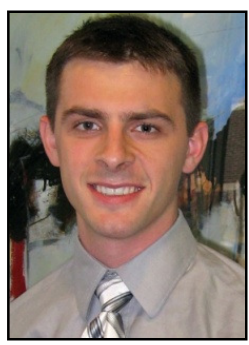

Brandon Smith is an aerospace engineer in the Entry Systems and Technology Division of NASA Ames Research Center. His current work involves design of deployable atmospheric entry vehicles and developmental flight instrumentation for the Orion Flight Test One heatshield. He received a B.S. and M.S. in Aerospace Engineering from Georgia Tech.

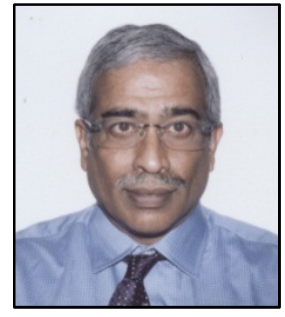

Dinesh Prabhu is a Senior Research Scientist with ERC, Inc., an onsite contractor at NASA Ames Research Center. He received his B.Tech. in Aeronautical Engineering from the Indian Institute of Technology at Madras, India, and his Ph.D. in Aerospace Engineering from the Iowa State University at Ames, Iowa. His interests are in modeling and simulation of hightemperature hypersonic flow fields, and in aerothermodynamic design of entry vehicles.

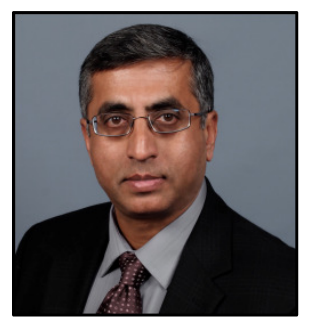

Ethiraj Venkatapathy is currently the Chief Technologist for the Entry Systems and Technology Division at NASA Ames Research Center. He received his B.Tech. in Aeronautical Engineering from the Indian Institute of Technology Madras, India, and his Ph.D. in Aerospace Engineering from the Iowa State University at Ames, Iowa. He is currently leading the technology development efforts, as the PI for the Conformable and Flexible Thermal Protection System (CFA-TPS), the mechanically deployable semi-rigid ADEPT project and Woven Thermal Protection System (WTPS) project. 